\title{
Open repair of chronic thoracic and thoracoabdominal aortic dissection using deep hypothermia and circulatory arrest
}

Joel Corvera, MD, Hannah Copeland, MD, David Blitzer, MD, Adam Hicks, BS, Joshua Manghelli, MD, Philip Hess, MD, and John Fehrenbacher, MD

\begin{abstract}
Background: Chronic dissection of the thoracic and thoracoabdominal aorta as sequela of a prior type A or B dissection is a challenging problem that requires close radiographic surveillance and prompt operative intervention in the presence of symptoms or aneurysm formation. Open repair of chronic thoracic and thoracoabdominal aortic dissection using deep hypothermia has been our preferred method to treat this complex pathology. The advantages of this technique include organ and spinal cord protection, the flexibility to extend the repair proximally into the arch, and the ability to limit ischemia to all vascular beds.
\end{abstract}

Methods: Open repair of arch by left thoracotomy and descending thoracic and thoracoabdominal aortic pathology using deep hypothermia was performed in 664 patients from 1995 to 2015 . A subset of this cohort had chronic thoracoabdominal aortic dissection $(n=196)$. All nonemergency cases received coronary angiography and echocardiography preoperatively. Significant coronary artery disease or severe aortic insufficiency was addressed before repair of the chronic dissection. In recent years, lumbar drains were placed preoperatively in the most extensive repairs (extents II and III). Important intercostal arteries from T8 to L1 were revascularized with smaller-diameter looped grafts. Multibranched grafts for the visceral segment have been preferred in recent years.

Results: Mean age of patients was $58 \pm 14$ years. Men comprised $74 \%$ of the cohort. Aortopathy was confirmed in $18 \%$ of the cohort. Prior thoracic aortic repair occurred in $57 \%$ of patients, and prior abdominal aortic repair occurred in $14 \%$ of patients. Prior type A aortic dissection occurred in $44 \%$ of patients, and prior type B occurred in $56 \%$ of patients. Operative mortality was $3.6 \%$, permanent spinal cord ischemia occurred in $2.6 \%$ of patients, permanent hemodialysis occurred in $0 \%$ of patients, and permanent stroke occurred in $1 \%$ of patients. Reexploration for bleeding was $5.1 \%$, and respiratory failure requiring tracheostomy occurred in $2.6 \%$. Postoperative length of stay was $11.9 \pm 9.7$ days. Reintervention for pseudoaneurysm or growth of a distal aneurysm was $6.9 \%$. The $1-, 5-$, and 10 -year survivals were $93 \%, 79 \%$, and $57 \%$, respectively.

Conclusions: Open repair of chronic thoracic and thoracoabdominal aortic dissection using deep hypothermia and circulatory arrest has low morbidity and mortality. The need for reintervention is low, and long-term survival is excellent. We believe that open repair continues to be the gold standard in patients who are suitable candidates for surgery. (J Thorac Cardiovasc Surg 2017;154:389-95)

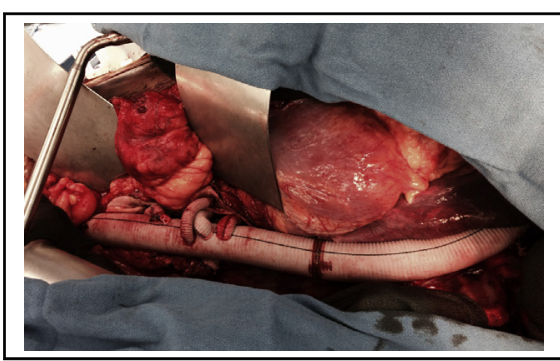

Completed repair of a chronic thoracoabdominal aortic dissection and aneurysm.

\section{Central Message}

Open repair of chronic thoracic and thoracoabdominal aortic dissection using deep hypothermia and circulatory arrest provides excellent early and late outcomes.

\section{Perspective}

For the suitable operative candidate, open repair of chronic thoracic and thoracoabdominal aortic dissection should remain the gold standard. All patients with connective tissue disorders should receive open repair. The open repair is definitive, rarely requires secondary procedures for the treated aortic segment, and has proven durability.

See Editorial Commentary page 396.

See Editorial page 387.

\footnotetext{
From the Division of Cardiothoracic Surgery, Indiana University School of Medicine, and Indiana University Health, Indianapolis, Ind.

Received for publication June 5, 2016; revisions received Feb 1, 2017; accepted for publication March 4, 2017; available ahead of print April 19, 2017.
}

Address for reprints: Joel Corvera, MD, Indiana University School of Medicine, Director of Thoracic Vascular Surgery, Indiana University Health, 1801 N. Senate Blvd, Suite 3300, Indianapolis, IN 46202 (E-mail: jcorvera@iuhealth.org). 0022-5223/ $\$ 36.00$

Copyright (C) 2017 by The American Association for Thoracic Surgery http://dx.doi.org/10.1016/j.jtcvs.2017.03.020 


\section{Abbreviation and Acronym \\ $\mathrm{IQR}=$ interquartile range}

\begin{abstract}
Scanning this QR code will take you to a supplemental video for the article.
\end{abstract}

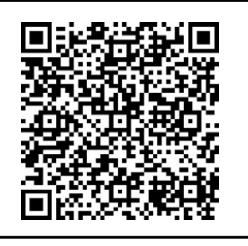

Chronic dissection of the thoracic and thoracoabdominal aorta as sequela of a prior type A or B dissection is a challenging problem that requires close radiographic surveillance and prompt operative intervention in the presence of symptoms or aneurysm formation. Every thoracoabdominal aortic dissection is unique in its combination of primary entry tear, reentry tears, fenestrations, extent of aortic involvement, involvement of branch vessels, flow distribution, and interplay between the true and false lumens. This complex pathology typically does not lend itself to a simple surgical solution.

Open repair of chronic thoracic and thoracoabdominal aortic dissection using deep hypothermia has been our preferred method to treat this complex pathology. The advantages of this technique include organ and spinal cord protection, the flexibility to extend the repair proximally into the arch, and the ability to limit ischemic injury to important vascular beds. The disadvantages include longer perfusion times and limited applicability to the ruptured aneurysm. The entire thoracoabdominal dissection can be addressed at once if the entire thoracoabdominal aorta is aneurysmal. Alternatively, only the aneurysmal portion needs to be replaced with fenestration of the dissection septum at the distal extent of the repair.

This study highlights our experience with open repair of arch by left thoracotomy and descending thoracic and thoracoabdominal aortic dissection using deep hypothermia and circulatory arrest.

\section{MATERIALS AND METHODS}

Institutional Review Board of Indiana University approval was obtained for the study. Individual patient consent was waived. From January 1995 to December 2015, 664 patients underwent open thoracic (by left thoracotomy) or thoracoabdominal aneurysm repair using deep hypothermia and circulatory arrest. The technique has been described. ${ }^{1,2}$ Briefly, anesthetic technique is composed of total intravenous anesthesia using propofol and remifentanil to allow preservation of motor-evoked and somatosensory-evoked potentials for spinal cord monitoring. Placement of a double-lumen endotracheal tube (Covidien Mallinckrodt Endobronchial tube, left; Medtronic, Inc, Minneapolis, Minn) or single-lumen tube with a bronchial blocker (Arndt Endobronchial Blocker Set; Cook Medical Inc, Bloomington, Ind) is used for selective airway control. Transcranial infrared oxygen sensors are placed on the left and right forehead (INVOS Cerebral/Somatic Oximeter; Somenetics Corporation, Troy, Mich). Motorevoked and somatosensory-evoked potentials (Cadwell Cascade stimulator-detector, disposable subdermal needle electrodes; Cadwell Laboratories, Inc, Kennewick, Wash) are recorded after induction of anesthesia for baseline values and are assessed intraoperatively after separation from cardiopulmonary bypass.

The patient is placed on full cardiopulmonary bypass typically through the left common femoral artery and vein. The arterial inflow temperature is reduced to achieve $15^{\circ} \mathrm{C}$. Once the heart fibrillates, decompression of the left ventricle is performed by placing a drainage catheter (Covidien Argyle, ventricular sump catheter, Medtronic, Inc, Minneapolis, Minn) through the left ventricular apex to low active suction. Once the patient has been cooled for 30 minutes with an arterial blood temperature of less than $20^{\circ} \mathrm{C}$, circulatory arrest is performed. The left ventricular sump catheter is turned off, the venous line is clamped, and arterial flow is stopped. A crossclamp is placed distal to the proposed proximal anastomosis on the descending thoracic aorta. Hypothermic low flow $(1-1.5 \mathrm{~L} / \mathrm{min})$ is started to the lower body while the proximal anastomosis is performed. If the entire transverse arch is to be replaced, perfusion catheters (Gundry Silicone RCSP cannula, Medtronic, Inc) are placed in the innominate and left common carotid arteries for bilateral selective antegrade cerebral perfusion at $10 \mathrm{~mL} / \mathrm{kg} / \mathrm{min}$. After the arch is reconstructed or the proximal anastomosis performed, perfusion is restored to the upper body (1 to $1.5 \mathrm{~L} / \mathrm{min}$ ) and the repair progresses stepwise proximally to distally. Intercostal arteries, 3 to 4 levels, from $\mathrm{T} 8$ to $\mathrm{L} 1$ are revascularized. When the abdominal aortic segment is opened, perfusion catheters (9F Pruitt Irrigation Occlusion Catheter; LeMaitre Vascular, Inc, Burlington, Mass) are placed into the orifices of the visceral vessels, and low-flow hypothermic blood perfusion is instituted at 200 to $300 \mathrm{~mL} / \mathrm{min}$. After reconstruction of the abdominal visceral segment is completed and the abdominal viscera reperfused, rewarming can commence with commensurate increases in cardiopulmonary bypass flow. Finally, the distal anastomosis is performed at the infrarenal aorta at the bifurcation or prior abdominal aortic graft. If the common iliac arteries are aneurysmal, iliac artery reconstructions also are performed.

As the patient is being rewarmed, the heart is defibrillated when the arterial inflow temperature is greater than $30^{\circ} \mathrm{C}$. Once rewarmed to tympanic and bladder temperatures greater than $35^{\circ} \mathrm{C}$, the patient is weaned from cardiopulmonary bypass. Vasopressor support is used to achieve a mean arterial pressure of 70 to $90 \mathrm{~mm} \mathrm{Hg}$. If motor-evoked potentials are not present in the bilateral lower extremities, the mean pressure is elevated to 90 to $110 \mathrm{~mm} \mathrm{Hg}$, and a lumbar drain is placed before leaving the operating room if it was not placed at the beginning of the procedure. Immediate postoperative hemoglobin is maintained at greater than $8 \mathrm{mg} / \mathrm{dL}$.

Recent technical changes in our surgical strategy for repair of all pathologies of thoracic and thoracoabdominal aneurysm have included the addition of arterial cannulation sites in the ascending aorta, distal aortic arch, proximal descending aorta, and left or right common carotid arteries to effort to avoid retrograde flow in the thoracoabdominal aorta. However, the majority (188/196) of the patients with chronic dissection had common femoral arterial cannulation for cardiopulmonary bypass. We also have championed the use of branched surgical grafts or smaller-diameter grafts to reconstruct the abdominal visceral arteries. In addition, revascularization of intercostal arteries is now performed using a small-diameter looped bypass graft. ${ }^{3}$ It is our thought that the use of smaller diameter grafts will reduce the likelihood of visceral or intercostal patch pseudoaneurysm.

Of 664 patients who underwent thoracic (by left thoracotomy) or thoracoabdominal aortic aneurysm repair, 196 patients, who comprise the current study, had chronic thoracoabdominal aortic dissection from prior type A or B dissection. Indications for repair included an overall maximal size of the aneurysmal aorta to be at least 50 to $55 \mathrm{~mm}$ in diameter or rapid growth of the aorta at a rate greater than or equal to $5 \mathrm{~mm}$ per year by computed tomography imaging (and since 2012 with center-line reconstruction). Patients with a known or suspected connective tissue disorder or a known 
familial aortopathy were repaired at a thoracic aortic diameter of $50 \mathrm{~mm}$, whereas those without connective tissue disorder or familial aortopathy were repaired at a thoracic aortic diameter of $55 \mathrm{~mm}$. An abdominal aortic component of $50 \mathrm{~mm}$ in the setting of a chronic thoracoabdominal aortic dissection also was an indication for surgery. Other indications include persistent and difficult to control hypertension (1 patient), chronic mesenteric ischemia (3 patients), intractable pain ( 2 patients), and a left common iliac artery aneurysm of $38 \mathrm{~mm}$ (1 patient).

All patients with elective operations received coronary angiography and echocardiography before aortic repair. Significant flow-limiting coronary stenosis was addressed before aneurysm repair with percutaneous coronary intervention or coronary artery bypass (sometimes performed concomitantly with aneurysm repair, $n=6 / 196$ ). Severe aortic valve insufficiency required aortic valve repair or replacement before repair of the chronic dissection.

Finally in 2013, we began preoperatively placing cerebrospinal fluid drains in our most extensive repairs, Crawford extents II and III, and in those patients who will have thoracoabdominal repair joining with a prior abdominal aortic graft or thoracic aortic graft. The reason for this change in technique was the increased number of paraplegia and paraparesis in patients with de novo extensive repairs (extents II or III) or completion thoracoabdominal replacement after prior aortic repair. A lumbar drain is not placed preoperatively in patients taking nonaspirin antiplatelet agents or oral anticoagulation or if there is a mycotic aneurysm or systemic infection or if the operation is emergency (Video 1).

\section{Statistical Analysis}

The study is retrospective. Continuous variables are represented as the mean with the standard deviation or median with interquartile range (IQR) as necessary. Categoric variables are represented as the number and percentage of the cohort. The Social Security Death Index, the Indiana Health Information Exchange, and the electronic medical record of the Indiana University School of Medicine were used to identify patients who died during the study period. Follow-up data were retrospectively collected, and the last known follow-up was recorded. Analysis of survival was performed using the method of Kaplan-Meier. The Kaplan-Meier estimates of survivor function and corresponding $95 \%$ confidence interval were calculated and plotted. The statistical software package used was called R: A Language and Environment for Statistical Computing, R Foundation for Statistical Computing, Vienna, Austria (http://www.R-project.org/).



Indiana University Health



VIDEO 1. Open repair of a thoracoabdominal aortic aneurysm using deep hypothermia and circulatory arrest. Video available at: http://www. jtcvsonline.org/article/S0022-5223(17)30451-8/addons.

\section{RESULTS}

Preoperative patient characteristics are listed in Table 1. The mean age of patients was $58 \pm 14$ years. Men comprised $74 \%$ of the cohort. Patients with known connective tissue disorder (confirmed Marfan syndrome, LoeysDietz syndrome, or familial aortopathy) comprised $18 \%$ of the cohort. Other comorbid disease is shown in Table 1. Chronic thoracoabdominal aortic dissection after prior repair of a type A aortic dissection occurred in $44 \%$ of patients. Chronic thoracoabdominal aortic dissection as a result of a type B aortic dissection occurred in $56 \%$ of patients. Prior thoracic aortic procedures occurred in $57 \%$ of patients, and prior abdominal aortic procedures occurred in $14 \%$ of patients.

The preoperative size of the thoracic or thoracoabdominal aorta was $57.2 \pm 11.0 \mathrm{~mm}$ (median, $55 \mathrm{~mm}$; IQR, $10 \mathrm{~mm}$ ). Twenty percent of patients had rapid growth $(>5 \mathrm{~mm}$ increase in size within a 12-month period with an aortic diameter $<50 \mathrm{~mm}$ ) as an indication for repair.

The extent of aortic replacement is shown in Table 2. Aortic replacement including total arch (proximal anastomosis to the ascending aorta) or partial arch (proximal anastomosis between the innominate and left subclavian arteries) in combination with the descending thoracic aorta comprised $13 \%$ of the cohort. Descending thoracic aortic replacement alone (proximal anastomosis distal to the left subclavian artery) occurred in $9 \%$ of the cohort. A Crawford extent I thoracoabdominal aortic aneurysm repair occurred in $31 \%$ of the cohort. Repair that extended through the visceral abdominal aorta was needed in approximately $50 \%$ of patients; $35 \%$ had extent II repair, $9 \%$ had extent III, and 3\% had extent IV. Aortoiliac or aortofemoral reconstruction was performed in $7 \%$ of patients. The mean

TABLE 1. Patient characteristics

\begin{tabular}{lcc}
\hline \multicolumn{3}{c}{$\mathbf{n}=\mathbf{1 9 6}$} \\
\hline Age (y) & $57.6 \pm 13.8$ & \\
Male & 145 & $(74.0)$ \\
Marfan syndrome & 23 & $(11.7)$ \\
Loeys-Dietz syndrome & 2 & $(1.0)$ \\
Familial aortopathy & 10 & $(5.1)$ \\
Prior CABG/PCI & 44 & $(22.4)$ \\
Hypertension & 174 & $(88.8)$ \\
COPD & 27 & $(13.8)$ \\
Hyperlipidemia & 90 & $(45.9)$ \\
Diabetes mellitus & 23 & $(11.7)$ \\
Chronic kidney disease & 41 & $(20.9)$ \\
Prior abdominal aortic procedure & 28 & $(14.3)$ \\
Prior thoracic aortic procedure & 112 & $(57.1)$ \\
Prior type A aortic dissection & 87 & $(44.4)$ \\
Prior type B aortic dissection & 109 & $(55.6)$ \\
\hline
\end{tabular}

Age is represented as mean \pm standard deviation. Values in parentheses represent percentages. $C A B G$, Coronary artery bypass grafting; $P C I$, percutaneous coronary intervention; $C O P D$, chronic obstructive pulmonary disease. 
TABLE 2. Extent of aortic replacement

\begin{tabular}{lcl}
\hline & $\mathbf{n}=\mathbf{1 9 6}$ & \\
\hline Descending thoracic aorta & 44 & $(22.4)$ \\
Descending only & 18 & $(9.2)$ \\
Partial arch + descending & 15 & $(7.7)$ \\
Total arch + descending & 11 & $(5.6)$ \\
Crawford extent I & 61 & $(31.1)$ \\
Crawford extent II & 69 & $(35.2)$ \\
Crawford extent III & 17 & $(8.7)$ \\
Crawford extent IV & 5 & $(2.6)$ \\
\hline
\end{tabular}

Values in parentheses represent percentages.

circulatory arrest time to the cerebrum was $24.7 \pm 9.1$ minutes, and the mean cardiopulmonary bypass time was $290.5 \pm 94.6$ minutes.

The operative outcomes are listed in Table 3. Overall operative mortality was $3.6 \%$. Neurologic deficit occurred in $3 \%$, but only $1 \%$ had permanent deficits. Spinal cord ischemia occurred in 11 patients, but only 5 patients $(2.6 \%)$ had permanent paraplegia or paraparesis.

A total of 104 patients $(53 \%)$ received segmental artery reimplantation. The need for segmental artery reimplantation was related to the extent of repair: extent I in 39 of 61 patients $(64 \%)$, extent II in 53 of 69 patients $(77 \%)$, extent III in 8 of 17 patients $(47 \%)$, extent IV in 2 of 5 patients $(40 \%)$, and descending with or without arch replacement in 2 of 44 patients $(5 \%)$. The number of patients with spinal cord ischemia who received intercostal reimplantation was $8(7.7 \%)$. The number of patients with spinal cord ischemia who did not have intercostal artery reimplantation was $3(3.3 \%, P=.22$ vs patients with intercostal reimplantation, Fisher exact test).

We placed lumbar drains preoperatively in only 15 patients (since 2013 when our use of preoperative spinal drains began for those with the highest risk of spinal cord ischemia). Of these, only 2 had transient paralysis or paraparesis and no patient had permanent motor deficit. Lumbar

TABLE 3. Operative results

\begin{tabular}{lcl}
\hline & $\mathbf{n}=\mathbf{1 9 6}$ & \\
\hline Operative mortality & 7 & $(3.6)$ \\
Permanent stroke & 2 & $(1.0)$ \\
Transient neurologic deficit & 4 & $(2.0)$ \\
Permanent paraplegia/paraparesis & 5 & $(2.6)$ \\
Transient spinal cord ischemia & 6 & $(3.1)$ \\
Acute renal failure (STS definition) & 10 & $(5.1)$ \\
Any hemodialysis & 8 & $(4.1)$ \\
Permanent hemodialysis & 0 & $(0)$ \\
Respiratory failure, tracheostomy & 5 & $(2.6)$ \\
Pneumonia & 29 & $(14.8)$ \\
Reexploration for bleeding & 10 & $(5.1)$ \\
Postoperative length of stay (d) & $11.9 \pm 9.7$ & \\
\hline
\end{tabular}

Postoperative length of stay is represented as mean \pm standard deviation. Values in parentheses represent percentages. STS, Society of Thoracic Surgeons. drains were placed in 36 patients $(18.4 \%)$ preoperatively or postoperatively and up to 30 days postoperatively. Ten of 36 patients experienced transient (6) or permanent (4) spinal cord ischemia. Only 1 patient $(0.6 \%)$ who did not receive a spinal drain had permanent paralysis.

Acute renal failure was a postoperative complication in $5.1 \%$ of patients, and any hemodialysis was needed in $4.1 \%$ of patients. However, no patients who survived the procedure required permanent hemodialysis. Postoperative pneumonia occurred in $15 \%$ of patients. Only $2.6 \%$ of patients required tracheostomy. Analysis of major complications and mortality according to the extent of aortic repair is shown in Table 4.

Reexploration for postoperative hemorrhage was required in 10 patients $(5 \%)$. Mean postoperative length of stay of survivors $(n=189 / 196)$ was $11.9 \pm 9.7$ days. Blood product use for the index hospitalization is listed in Table 5. The median blood product administration for the hospitalization was 4 units (IQR, 13 units).

Follow-up after surgery for distal chronic aortic dissection occurs at 1 month after discharge from the hospital and at 12 months postoperatively with computed tomography imaging. Subsequent imaging occurs at 30 months and 54 months postoperatively. Imaging can occur at more frequent intervals depending on aneurysm change or growth or the development of symptoms. Of the operative survivors, 186 of $189(98 \%)$ had at least 1 follow-up visit. Mean follow-up for our series was $46.9 \pm 47.4$ months (median follow-up, 30.9 months; IQR, 59 months). Reintervention was uncommon. Two patients required reoperation for infected aortic grafts. Pseudoaneurysm of a visceral or intercostal island anastomosis occurred in 6 patients $(3.1 \%)$. Reoperation for growth of a distal aneurysm was performed in 7 patients $(3.6 \%)$.

Figure 1 shows the long-term survival of the cohort using Kaplan-Meier analysis including 95\% confidence intervals and number of patients at risk. The 1-, 3-, 5-, and 10-year survivals were $93 \%, 86 \%, 79 \%$, and $57 \%$, respectively. Median survival was 10.7 years.

\section{DISCUSSION}

Open repair of chronic distal thoracic and thoracoabdominal aortic dissection has good operative outcomes and long-term survival. ${ }^{4-8}$ The technique of deep hypothermia and circulatory arrest has a low mortality and low complication rate in thoracic and thoracoabdominal aneurysm repair, as seen in our series and other series. ${ }^{1,2,9-11}$ In the current study, mortality for operative repair of chronic distal aortic dissection was not associated with a greater extent of repair or the need for arch replacement. The reason for this is not clear; however, hypothermia is imperative in arch replacement and is likely protective against mortality in other extensive repairs. There was more spinal cord ischemia 
TABLE 4. Major complications and mortality by extent of aortic repair

\begin{tabular}{|c|c|c|c|c|c|c|c|}
\hline & $\begin{array}{c}\text { Descending } \\
\text { only }(n=18)\end{array}$ & $\begin{array}{c}\text { Partial arch }+ \text { descending } \\
(\mathbf{n}=\mathbf{1 5})\end{array}$ & $\begin{array}{c}\text { Total arch }+ \text { descending } \\
(\mathbf{n}=\mathbf{1 1})\end{array}$ & $\begin{array}{l}\text { Extent I } \\
(\mathbf{n}=61)\end{array}$ & $\begin{array}{c}\text { Extent II } \\
(n=69)\end{array}$ & $\begin{array}{c}\text { Extent III } \\
(\mathbf{n}=\mathbf{1 7})\end{array}$ & $\begin{array}{c}\text { Extent IV } \\
(\mathbf{n}=\mathbf{5})\end{array}$ \\
\hline Mortality & $2(11.1)$ & $1(6.7)$ & $0(0)$ & $1(1.6)$ & $2(2.9)$ & $1(5.9)$ & $0(0)$ \\
\hline Paralysis/paraparesis & $1(5.6)$ & $0(0)$ & $0(0)$ & $1(1.6)$ & $7(10.1)$ & $2(11.8)$ & $0(0)$ \\
\hline Permanent & $1(5.6)$ & $0(0)$ & $0(0)$ & $0(0)$ & $2(2.9)$ & $2(11.8)$ & $0(0)$ \\
\hline Temporary & $0(0)$ & $0(0)$ & $0(0)$ & $1(1.6)$ & $5(7.2)$ & $0(0)$ & $0(0)$ \\
\hline Acute renal failure & $2(11.1)$ & $0(0)$ & $0(0)$ & $0(0)$ & $7(10.1)$ & $1(5.9)$ & $0(0)$ \\
\hline Any hemodialysis & $2(11.1)$ & $0(0)$ & $0(0)$ & $0(0)$ & $5(7.2)$ & $1(5.9)$ & $0(0)$ \\
\hline Stroke & $0(0)$ & $0(0)$ & $0(0)$ & $0(0)$ & $2(2.9)$ & $0(0)$ & $0(0)$ \\
\hline Tracheostomy & $1(5.6)$ & $1(6.7)$ & $1(9.1)$ & $0(0)$ & $2(2.9)$ & $0(0)$ & $0(0)$ \\
\hline
\end{tabular}

Values in parentheses represent percentages.

and renal failure in the type II repair cohort, as would be expected in these patients with the most extensive repair; however, there was no statistically significant difference compared with lesser extents of repair. Deep hypothermia may be able to equalize mortality across all extents of repair, including arch repair. Deep hypothermia may ameliorate major complications from the most extensive and complex thoracoabdominal repairs; however, there were too few events in this series to make meaningful statistical comparisons. Our clinical impression is that the most extensive repairs (extent II and III thoracoabdominal repairs) carry the highest risk of major complication, including spinal cord ischemia and renal failure.

One reported potentially catastrophic disadvantage of the technique of deep hypothermia for thoracic and thoracoabdominal aneurysm repair is parenchymal lung hemorrhage requiring lung resection. In separate series by Safi and colleagues ${ }^{12}$ and Coselli and colleagues, ${ }^{13}$ high mortality rates and hemorrhagic lung complications were reported, and they advocated against routine use of deep hypothermia. We had 1 patient who required lung resection for intractable parenchymal hemorrhage, and this patient did not survive. Adequate decompression of the left ventricle and pulmonary vascular bed during the period of hypothermic fibrillation and minimizing the manipulation of the lung during the period of anticoagulation help to avoid this potentially fatal complication. Although mild parenchymal contusion is not infrequent, it did not prolong ventilation times or increase the risk of respiratory failure requiring tracheostomy in our series because we are vigilant in ensuring that the left ventricle is adequately decompressed.

The perfusion strategy using deep hypothermia in the repair of chronic distal aortic dissection may have the best surgical outcomes compared with other perfusion strategies. $^{2,6}$ The advantages of full cardiopulmonary bypass and deep hypothermia include organ protection including the spinal cord and kidneys, the ability to extend the repair proximally into the arch as needed, and the limitation of ischemia to important vascular beds. ${ }^{9-11}$ Protection of the spinal cord with the combination of hypothermia and aggressive intercostal reimplantation provides low rates of permanent paralysis. We believe that the addition of preoperative spinal drains in our most extensive repairs can lower our paraplegia rate even further as seen in our most recent extensive repairs after 2013 with no permanent spinal cord deficit.

Perfusion times are certainly longer with the technique of deep hypothermia, but we have not encountered significant postoperative bleeding and coagulopathy as evidenced by our low rate of reexplorations for bleeding and low need for blood product transfusion. Other surgical techniques using left heart bypass cannot address arch pathology proximal to the left subclavian artery. Organ protection can be suboptimal with periods of warm ischemia or hypoperfusion to various vascular beds. Historical series of open repair of chronic distal aortic dissection using normothermic techniques report mortality of $10 \%$ to $15 \%{ }^{14,15}$ Mortality using left heart bypass techniques is $8.6 \%$ in a contemporary series; however, in this series, repair was limited to the descending thoracic aorta. ${ }^{8}$ Other contemporary series describe mortality of $5.8 \%$ to $9.6 \%$ using a variety of perfusion techniques, including deep hypothermia and circulatory arrest in a minority of patients. ${ }^{4-6}$ Although it is difficult to directly compare perfusion strategies, our series compares favorably with these while including complex arch and aortoiliac repairs. Deep

TABLE 5. Blood product use for the hospitalization

\begin{tabular}{lccc}
\hline & Mean & Median & 25th percentile \\
\hline Packed red blood cells (units) & $4.8 \pm 6.1$ & 3 & 1 \\
Fresh-frozen plasma (units) & $2.1 \pm 3.0$ & 0 & 0 \\
Platelet pheresis (units) & $1.2 \pm 1.5$ & 1 & 0 \\
Cryoprecipitate (10 units) & $0.9 \pm 1.6$ & 0 & 0 \\
\hline
\end{tabular}




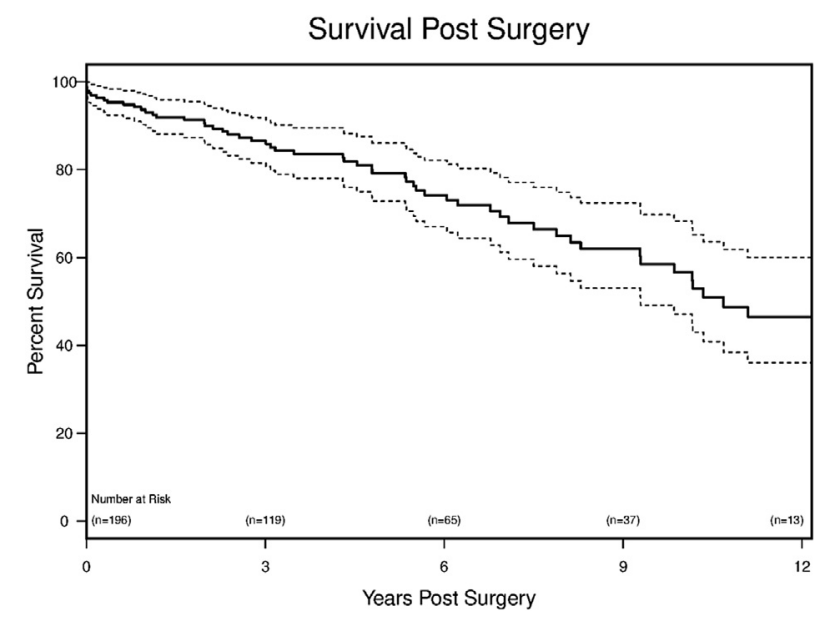

FIGURE 1. Kaplan-Meier survivor function with $95 \%$ confidence intervals and number at risk at 3-year intervals.

hypothermia with circulatory arrest has been our preferred technique to repair thoracoabdominal aortic aneurysms of all extents and in particular chronic thoracic and thoracoabdominal aortic dissection.

Open repair of chronic thoracic and thoracoabdominal aortic dissection using deep hypothermia for the suitable operative candidate has low morbidity and mortality. The average age of our cohort was 58 years. This young age reflects our patient population with de novo type B aortic dissection, prior type A dissection, familial aortopathy, and connective tissue disorders. Those with connective tissue disorders and familial aortopathy comprise approximately $20 \%$ of our cohort. The mean age of those without known connective tissue disorder or known familial aortopathy was $61 \pm 12$ years, reflecting the relatively young patient with aortic dissection in Indiana.

We intervened on distal chronic aortic dissection when the thoracic aorta was $55 \mathrm{~mm}$ in patients without known aortopathy and $50 \mathrm{~mm}$ with known or suspected aortopathy. We also intervened on chronic thoracoabdominal dissection when the abdominal aorta was $50 \mathrm{~mm}$. Kim and colleagues ${ }^{16}$ stated that the risk of an aortic event of an unrepaired descending or thoracoabdominal aneurysm ranges from $5.5 \%$ to $8.0 \%$ in aortic diameters as small as $50 \mathrm{~mm}, 7.2 \%$ to $11.2 \%$ at an aortic diameter of $55 \mathrm{~mm}$, and $9.3 \%$ to $15.6 \%$ at an aortic diameter of $60 \mathrm{~mm} .{ }^{16} \mathrm{We}$ believe that size for size, chronic dissection is a more lethal problem than degenerative atherosclerotic aneurysm and have chosen to be more aggressive in repairing them especially given our excellent surgical outcomes. Although repairing a smaller aneurysm may be technically easier and therefore may have a decreased risk of mortality, the size of the aneurysm did not correlate with an increased risk of mortality in our series. In fact, there was no mortality in those who had aneurysms $65 \mathrm{~mm}$ or greater $(19 \%$ of the cohort).
Long-term survival is good in our study. The 10-year survival is approximately $60 \%$. The need for reintervention is low-very low for infected surgical grafts and surprisingly low for aneurysm formation of the distal aorta. Although it may be possible that our patients were cared for at other institutions for complications of the repair or for distal aneurysm formation, we believe this number to be low because the Indiana University School of Medicine is the only institution in Indiana that performs these procedures to a great extent.

\section{Study Limitations}

The limitations of this study are those that are inherent to an observational, single-center retrospective review. The outcomes in this study may not be generalizable because the operations described were predominantly performed by 2 surgeons (J.C. and J.F.) at 1 tertiary care hospital. Our analysis of survival using the institutional medical record, the Indiana Health Information Exchange data set, and the Social Security Death Index (which is an incomplete data set) is limited by the frequency and completeness of follow-up of our patient population. The last known follow-up date or date of death was used in the survival analysis with the consequence of a significant number of censored patients.

There is great interest in using endovascular techniques in the treatment of chronic distal aortic dissection. Endovascular repair of chronic thoracoabdominal aortic dissection can be accomplished with low morbidity and mortality and usually is able to affect false lumen thrombosis and aortic remodeling at the level of the endograft in the thoracic aorta. ${ }^{17-20}$ However, aortic remodeling is uncommon in the abdominal aorta, and reintervention is common. $^{20}$ The currently available thoracic endografts are limited in their application to complex thoracoabdominal aortic dissection with multiple visceral arteries coming off the false lumen, multiple fenestrations, and severely compressed true lumen. Also, the use of thoracic endografts in connective tissue disorders may not be prudent. The longterm outcomes and durability of thoracic endograft repair for chronic distal aortic dissection are not known. In open repair, aortic remodeling is never in question, reintervention is rare, and success is not limited by complex anatomy. The durability of open repair is excellent. The mortality and morbidity of this series compare admirably with that of endograft series of chronic distal aortic dissection, but with markedly less reintervention and proven long-term survival.

\section{CONCLUSIONS}

Open and endovascular repair should not be competing modalities. Rather, they should be complementary. For the young or otherwise suitable operative candidate, open repair should remain the gold standard. Ideally, all patients with connective tissue disorders should have open repair. 
However, for the patient with advanced age and multiple comorbidities making them a poor surgical candidate, endovascular repair may be the procedure of choice if the anatomy of the aorta is favorable. As the technology for endovascular devices advances and branched or fenestrated thoracoabdominal systems become widely available, the paradigm for open versus endovascular repair will likely change.

\section{Conflict of Interest Statement}

H.C.'s husband is a consultant for SynCardia Systems, LLC. J.F. is an advisor to CryoLife, Inc. All other authors have nothing to disclose with regard to commercial support.

The authors thank Colin Terry, MS, of the Methodist Research Institute, Indianapolis, Indiana, for the statistical analysis of this study.

\section{References}

1. Fehrenbacher JW, Siderys H, Terry C, Kuhn J, Corvera JS. Early and late results of descending thoracic and thoracoabdominal aneurysm open repair using deep hypothermia and circulatory arrest. J Thorac Cardiovasc Surg. 2010;140: S154-60.

2. Corvera JS, Fehrenbacher JW. Open repair of chronic aortic dissection using deep hypothermia and circulatory arrest. Ann Thorac Surg. 2012;94:78-83.

3. Woo EY, Mcgarvey M, Jackson BM, Bavaria JE, Fairman RM, Pochettino A. Spinal cord ischemia may be reduced via a novel technique of intercostal artery revascularization during open thoracoabdominal aneurysm repair. J Vasc Surg. 2007;46:421-6.

4. Zoli S, Etz CD, Roder F, Mueller CS, Brenner RM, Bodian CA, et al. Long-term survival after open repair of chronic distal aortic dissection. Ann Thorac Surg. 2010;89:1458-66.

5. Pujara AC, Roselli EE, Hernandez AV, Vargas Abello LM, Burke JM, Svensson LG, et al. Open repair of chronic distal aortic dissection in the endovascular era: implications for disease management. J Thorac Cardiovasc Surg. 2012; 144:866-73.

6. Conway AM, Sadek M, Lugo J, Pillai JB, Pellet Y, Panagopoulos G, et al. Outcomes of open surgical repair for chronic type B aortic dissections. J Vasc Surg. 2014;59:1217-23.

7. Van Bogerijen GHW, Patel HJ, Williams DM, Yang B, Dasika NL, Eliason JL, et al. Propensity adjusted analysis of open and endovascular thoracic aortic repair for chronic type B dissection: a twenty-year evaluation. Ann Thorac Surg. 2015 99:1260-6.

8. Estrera AL, Jan A, Sandhu H, Shalhub S, Medina-Castro M, Nguyen TC, et al. Outcomes of open repair for chronic descending thoracic aortic dissection. Ann Thorac Surg. 2015;99:786-94.

9. Kulik A, Castner CF, Kouchoukos NT. Outcomes after thoracoabdominal aortic aneurysm repair with hypothermic circulatory arrest. J Thorac Cardiovasc Surg. 2011;141:953-60.

10. Kouchoukos NT, Masetti P, Murphy SF. Hypothermic cardiopulmonary bypass and circulatory arrest in the management of extensive thoracic and thoracoabdominal aortic aneurysms. Semin Thorac Cardiovasc Surg. 2003;15:333-9.

11. Fehrenbacher JW, Hart DW, Huddleston E, Siderys H, Rice C. Optimal endorgan protection for thoracic and thoracoabdominal aneurysm repair using deep hypothermic circulatory arrest. Ann Thorac Surg. 2007;83:1041-6.

12. Safi HJ, Miller CC, Subramaniam MH, Campbell MP, Iliopoulos DC, O'Donnell JJ, et al. Thoracic and thoracoabdominal aneurysm repair using cardiopulmonary bypass, profound hypothermia and circulatory arrest via left side of chest incision. J Vasc Surg. 1998;28:591-8.

13. Coselli JS, Bozinovski J, Cheung C. Hypothermic circulatory arrest: safety and efficacy in the operative treatment of descending thoracic and thoracoabdominal aortic aneurysms. Ann Thorac Surg. 2008;85:956-64.

14. Fann JI, Smith JA, Miller DC, Mitchell RS, Moore KA, Grunkemeier G, et al Surgical management of aortic dissection during a 30-year period. Circulation. 1995;92:II113-21.

15. Safi HJ, Miller CC III, Reardon MJ, Iliopoulos DC, Letsou GV, Espada R, et al Operation for acute and chronic aortic dissection: recent outcome with regard to neurologic deficit and early death. Ann Thorac Surg. 1998;66:402-11.

16. Kim JB, Kim K, Lindsay ME, MacGillivray T, Isselbacher EM, Cambria RP et al. Risk of rupture or dissection in descending thoracic aortic aneurysm. Circulation. 2015;132:1620-9.

17. The VIRTUE registry investigators. The VIRTUE registry of type B thoracic dissections—study design and early results. Eur J Vasc Endovasc Surg. 2001;41: 159-66.

18. Parsa CJ, Williams JB, Bhattacharya SD, Wolfe WG, Daneshmand MA McCann RL, et al. Midterm results with thoracic endovascular aortic repair for chronic type B aortic dissection with associated aneurysm. J Thorac Cardiovasc Surg. 2011;141:322-7.

19. Xu SD, Huang FJ, Yang JF, Li ZZ, Yang S, Du JH, et al. Early and midterm results of thoracic endovascular aortic repair of chronic type B aortic dissection. $J$ Thorac Cardiovasc Surg. 2010;139:1548-53.

20. Leshnower BG, Szeto WY, Pochettino A, Desai ND, Moeller PJ, Nathan DP, et al Thoracic endografting reduces morbidity and remodels the thoracic aorta in DeBakey III aneurysms. Ann Thorac Surg. 2013;95:914-21.

Key Words: thoracoabdominal aneurysm, chronic aortic dissection, deep hypothermia 